Post-print of: Journal of the Science of Food and Agriculture 96(5). 1643-1647 (2015)

\title{
Screening of anthocyanins in single red grapes using a non-destructive method based on the near infrared hyperspectral technology and chemometrics
}

\author{
Jesús Raúl Martínez-Sandoval, ${ }^{a}$ Julio Nogales-Bueno, ${ }^{b}$ \\ Francisco José Rodríguez-Pulido, José Miguel Hernández-Hierro, ${ }^{\mathrm{b}}$ \\ Manuel Alberto Segovia-Quintero, ${ }^{\mathrm{c}}$ Miguel Enrique Martínez-Rosas ${ }^{\mathrm{a}}$ and \\ Francisco José Heredia ${ }^{b^{*}}$
}

\begin{abstract}
BACKGROUND: Anthocyanins are the main compounds responsible for the colour of red wines and therefore it may be important to evaluate the content of the aforesaid secondary metabolites during grape ripening due to the crucial importance to determine wine colour. Nowadays, there is a growing demand of rapid and non-destructive analytical tools for analysing grapes, such as the emerging hyperspectral analysis.

RESULTS: The hyperspectral images of intact grapes (Vitis vinifera L. cv. Tempranillo, Graciano, Garnacha and Mazuelo red grape from vineyards located in the D.O.Ca. Rioja at two different developmental stages) were recorded using a near infrared hyperspectral imaging device $(900-1700 \mathrm{~nm})$. Reference values of anthocyanins were obtained by HPLC-DAD. Calibrations were performed by modified partial least squares regression and present a good potential (coefficient of determination of 0.72 and standard error of cross-validation values of 0.78 and $0.70 \mathrm{mg}$ per grape for total and non-acylated anthocyanins respectively).

CONCLUSION: The procedure reported here presents a good potential for a fast and reasonably inexpensive screening of these compounds in intact single berries. Moreover, the heterogeneity of anthocyanins within the same ripeness stage could be evaluated using this non-detructive tool.
\end{abstract}

Keywords: anthocyanins; grapes; hyperspectral imaging; near infrared; chemometrics

\section{INTRODUCTION}

Consumers value the quality characteristics of wine (sensory parameters such as aroma, colour and flavour) produced from high-quality grapes enough to pay higher prices so grape prices are closely linked to grape quality. Red wine colour is strongly influenced by phenolic content of grapes. Among them, anthocyanins are responsible for the colour of red wines and their interactions with other phenolic compounds are of crucial importance to determine the colour changes observed during ageing. ${ }^{1}$ These compounds, which are located in red grape skins, are responsible for tissue pigmentation and provide colours that range from reddish to purplish. ${ }^{2}$

In this context, it may be important to evaluate the content of these secondary metabolites in grapes. Rapid analytical methods, such as hyperspectral analysis, may be useful for the aforementioned task and increase the number of samples that could be analysed. Hyperspectral imaging is an emerging and rapid technique for non-destructive food analysis. ${ }^{3}$ The development of hyperspectral analysis methods for use in the food sector in the recent past has risen considerably..$^{-5}$ Our previous work has demonstrated the potential of near infrared (NIR) hyperspectral imaging to discriminate between four red grape cultivars ${ }^{6}$ and also to quantify anthocyanins in two red grape cultivars from a warm climate with acceptable accuracy for screening purposes. ${ }^{7}$ As stated in the aforementioned study, factors such as grape

Correspondence to: Francisco José Heredia, Food Colour \& Quality Laboratory, Department of Nutrition \& Food Science, Universidad de Sevilla, Facultad de Farmacia, 41012 Seville, Spain. E-mail: heredia@us.es

a Autonomous University of Baja California (UABC), Faculty of Engineering, Architecture and Design (FIAD), Kilometro 106 carretera Tijuana-Ensenada, Ensenada, Baja California, Mexico

b Food Colour \& Quality Laboratory, Department of Nutrition \& Food Science, Universidad de Sevilla, Facultad de Farmacia, 41012 Seville, Spain

c Center of Scientific Research and Higher Education of Ensenada (CICESE), Carretera Ensenada-Tijuana No. 3918 Zona Playitas, CP: 22860, Ensenada, Baja California, Mexico 
varieties or production areas should be studied in the development of these models. Furthermore, heterogeneity can be also found in a single sampling point and it describes a Gaussian bell-shaped distribution. ${ }^{8}$ Factors such as the influence of sunlight exposure and temperature on the heterogeneity of polyphenolic compounds. ${ }^{9,10}$ Taking that into account, it would be desirable to analyse single grapes in order to allocate the corresponding reference value to each single sample instead of an average reference value. This methodology may allow individual berries to be sorted according to their composition and then the same samples could be used for further purposes.

The area where the present study was conducted involved the wine-producing region of D.O.Ca. Rioja, in northern Spain, which has vineyards extending over 63593 ha. Vitis vinifera L. cv. Tempranillo is the most widely grown red grape variety in Spain and it is cultivated in 75\% of the D.O.Ca. Rioja. Graciano, which is an autochthonous cultivar to the previously mentioned region, is less known, but it is used as an integral component of many Rioja wines because it is considered to contribute significantly to the quality of the wine. Furthermore, cultivars such as Garnacha and Mazuelo are also grown in this area. ${ }^{11}$

The aim of this study was to evaluate the potential of near infrared hyperspectral imaging for the screening of anthocyanins using intact single grapes as sample presentation form. Moreover, this is the first time that the aforesaid four different cultivars from La Rioja (Spain) have been jointly used for this purpose.

\section{MATERIALS AND METHODS Grape samples}

Vitis vinifera L. cv. Tempranillo (two different vineyards), Graciano, Garnacha and Mazuelo (the name employed in La Rioja for Carignan) red grape samples were collected from vineyards located in the D.O.Ca. Rioja. La Rioja is divided into regions according to their agroclimatic characteristics. All samples were collected from vineyards located in Rioja Media, which is under the influence of a Mediterranean climate. Red grapes were collected at two different developmental stages during berry maturity in the 2012 vintage: harvest time and over-ripening. Harvest time and over-ripening dates were selected in agreement with the cellar staff internal criteria [Bodegas RODA S.A. (Haro, La Rioja, Spain)]. Individual grapes were randomly separated from the bunches. Five berries were taken into account for each cultivar and developmental stage with the exception of Tempranillo. In the case of Tempranillo, 20 berries were used since two different vineyards were taken into account (i.e. five berries $\times$ two vineyards $\times$ two developmental stages). $A$ total of 50 samples were used. Berries were immediately frozen and stored at $-20^{\circ} \mathrm{C}$ until analyses were performed.

\section{Hyperspectral image acquisition}

Equipment and procedure used to image recording are described in detail in Hernández-Hierro et al. ${ }^{7}$ and Nogales-Bueno et al. ${ }^{6,12}$ The main components of the hyperspectral imaging device (Infaimon S.L., Barcelona, Spain) were the illumination source, optics (mirror scanner and lens), spectrograph, camera and computer. The system comprised a Xenics ${ }^{\circledR}$ XEVA-USB InGaAs camera $(320 \times 256$ pixels; Xenics Infrared Solutuions, Inc., Leuven, Belgium), a spectrograph (Specim ImSpector N17E Enhanced; Spectral Imaging Ltd., Oulu, Finland) covering the spectral range between 900 and $1700 \mathrm{~nm}$ (spectral resolution of $3.25 \mathrm{~nm}$ ), two 70-W tungsten iodine halogen lamps (Prilux ${ }^{\circledR}$, Barcelona, Spain) mounted as source light, a mirror scanner (Spectral Imaging Ltd) and a computer system. Hyperspectral images were recorded using a $50 \mathrm{~Hz}$ frame rate and an exposure time of $9 \mathrm{~ms}$ using the instrument acquisition software SpectralDAQ v. 3.62 (Spectral Imaging Ltd). A two point reflectance calibration was used. A Spectralon ${ }^{\circledR}$ ceramic tile (Labsphere Inc., North Sutton, NH, USA) was used as a white reference while dark current was recorded by taking a measurement after covering the spectrograph lens with a cup and closing the shutter. Samples were thawed and tempered at room temperature (approx. $2 \mathrm{~h}$ ) and the hyperspectral individual single grape image was recorded. The spatial resolution of images was $320 \times 354$ pixels. Every grape had more than 200 pixels, and they all were considered for measuring the average spectrum of each one. Then, the calibration and segmentation processes were performed and the average spectral profile for each individual grape was saved as the $\log (1 / R)$ data in the effective wavelength $950-1650 \mathrm{~nm}$ regions. The whole data set was constituted by 50 samples and $215 \log (1 / R)$ data points per sample.

\section{Anthocyanin extraction and chromatographic analysis}

Grape skins were separated manually from the whole grapes. Individual grape skins were macerated twice at $4^{\circ} \mathrm{C}$ in $10 \mathrm{~mL}$ of methanol containing $0.1 \%$ of $12 \mathrm{~mol} \mathrm{~L}^{-1} \mathrm{HCl}$ until the skins were colourless. In order to assist extraction, the methanolic mixtures were sonicated with an ultrasound device (JP Selecta, Barcelona, Spain) for $30 \mathrm{~min}$ prior to the $24 \mathrm{~h}$ maceration step. Methanolic phases were centrifuged $(830 \times g, 10 \mathrm{~min})$, successively pooled and finally made up to $25 \mathrm{~mL}$ with the extraction solvent. One aliquot of $1 \mathrm{~mL}$ was taken and a few microlitres of $0.1 \mathrm{~mol} \mathrm{~L}^{-1} \mathrm{HCl}$ was added and the extract was concentrated under vacuum at $30^{\circ} \mathrm{C}$ (Eppendorf Concentrator Plus, Hamburg, Germany) until methanol was removed and finally made up to 1 $\mathrm{mL}$ with $0.1 \mathrm{~mol} \mathrm{~L}^{-1} \mathrm{HCl}$. The aqueous extract was filtered through $0.45 \mu \mathrm{m}$ pore-size filters and directly injected into the chromatographic system to determine the anthocyanins. Anthocyanins chromatographic analysis was carried out following a modification of García-Marino et al..$^{13}$ as described in Hernández-Hierro et al. ${ }^{7}$ Results were expressed as $\mathrm{mg}$ of malvidin-3-O-glucoside equivalents per grape. All analyses were performed in duplicate.

\section{Data analysis}

Principal component analysis (PCA), an unsupervised pattern recognition technique, was used in order to provide information about the latent structure of spectral matrix $(X)$ prior to quantitative analysis. ${ }^{14,15}$

Calibrations were performed by modified partial least squares regression (MPLS) ${ }^{14}$ using the raw spectral data and testing different spectral pre-treatments and allocating the corresponding reference values $(Y)$ to each sample. In the aforesaid method, the group of calibration samples is divided into a series of subsets in order to perform cross-validation, set the number of PLS factors, reduce the possibility of overfitting ${ }^{14}$ and remove chemical outliers. Using the $T \geq 2.5$ criterion, samples that presented a high residual value when they were predicted were eliminated from the set. Finally, validation errors are combined into a single figure, the standard error of cross-validation (SECV). The $k$-folds cross-validation is a well-established method that segments the data into $k$ partitions. A special case of the $k$-fold cross-validation method sets $k=$ number of samples, the size of the data set (leave-one-out). This approach has been used in the present study. Spectral pre-treatments are usually applied to NIR raw 

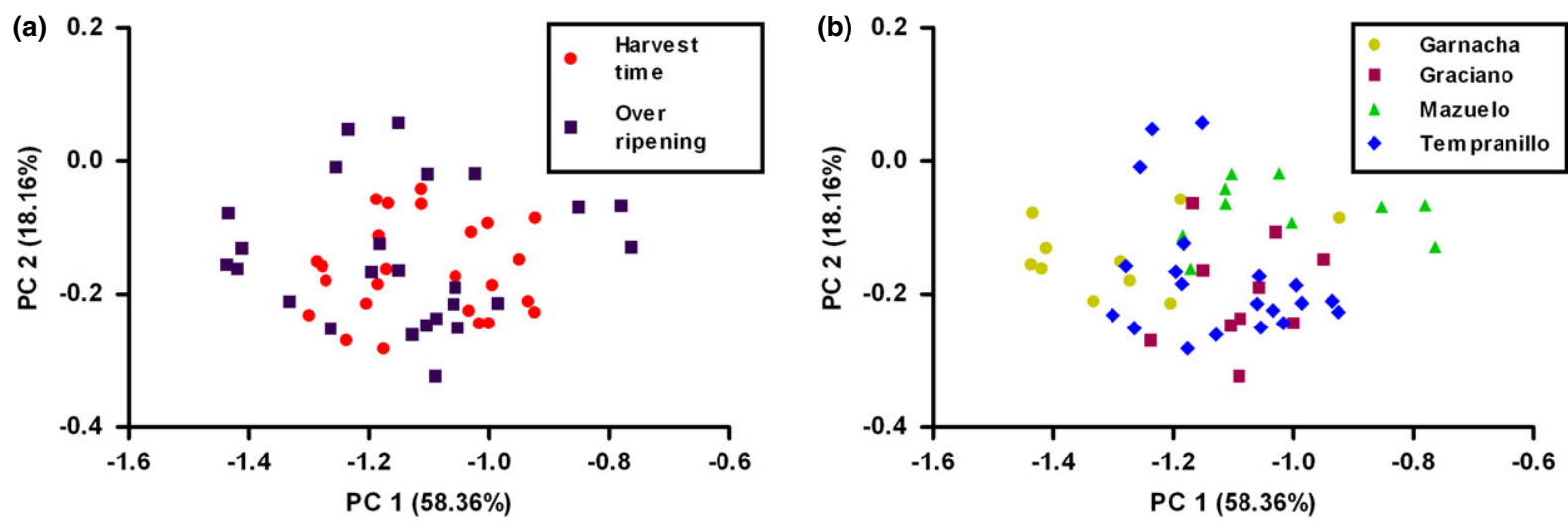

Figure 1. Score plot of grape samples in the plane defined by PC1 and PC2. (a) Different stages of ripening or (b) different cultivars.

data. ${ }^{16,17}$ Furthermore, the effect of differentiation and variations in spectral ranges were tested in the development of the NIRS calibrations. The software used was Win ISI ${ }^{\circledR}$ (v1.50) (Infrasoft International, LLC, Port Matilda, PA, USA).

\section{RESULTS AND DISCUSSION Chemical analysis}

Up to 11 anthocyanins were identified and their sum was expressed as total anthocyanins. Moreover, taking into account their basic structures anthocyanins were grouped as non-acylated anthocyanins (delphinidin-3-O-glucoside, cyanidin3-O-glucoside, petunidin-3-O-glucoside, peonidin-3-O-glucoside, malvidin-3-O-glucoside) and acylated anthocyanins [malvidin3-O-(6"-acetyl) glucoside, cyanidin-3-O-(6"'-p-coumaroyl) glucoside (trans), petunidin-3-O-(6"- $p$-coumaroyl) glucoside (trans), malvidin-3-O-(6" - $p$-coumaroyl) glucoside (cis), peonidin-3-O-(6" $p$-coumaroyl) glucoside (trans) and malvidin-3-O-(6" $-p$-coumaroyl) glucoside (trans)]. Total anthocyanins contents in the grape samples ranged from 1.0 to $8.4 \mathrm{mg}$ per grape with a standard deviation value of $1.5 \mathrm{mg}$ per grape. Non-acylated anthocyanins contents in the grape samples ranged from 0.9 to $6.8 \mathrm{mg}$ per grape with a standard deviation value of $1.3 \mathrm{mg}$ per grape. Acylated anthocyanins could be calculated as the difference between total and non-acylated anthocyanins.

\section{Chemometric analysis}

As part of the quantitative analysis, a standard normal variate (SNV $2,5,5,1)$ spectral pre-treatment was applied to the aforementioned spectral matrix in the $950-1650 \mathrm{~nm}$ range. Mathematical treatment is denoted as a,b,c,d, where the first digit is the number of the derivative; the second is the gap over which the derivative is calculated; the third is the number of data points in a running average or smoothing, and the fourth is the second smoothing. ${ }^{14}$ Then, principal component analysis was carried out in order to look for spectral outliers. Overall, the spectral variability explained was 97\% using 12 principal components and Mahalanobis distances $(H)$ from the mean spectrum of the entire sample set were calculated in this hyperspace. Samples were ranked in order of their $H$ values and the $H>3$ criterion was applied, although $H$-outliers were not found. Figure 1 shows the scores of the grape samples in the plane defined by the first and second principal components, which described $58.36 \%$ (PC1) and $18.16 \%$ (PC2) of the variability in the spectral data. In this plot, differences between the ripening stages (Fig. 1a) or cultivars (Fig. 1b) are not apparent since samples were completely overlapped in this plane. Since there were not differences neither between cultivars nor between the ripening

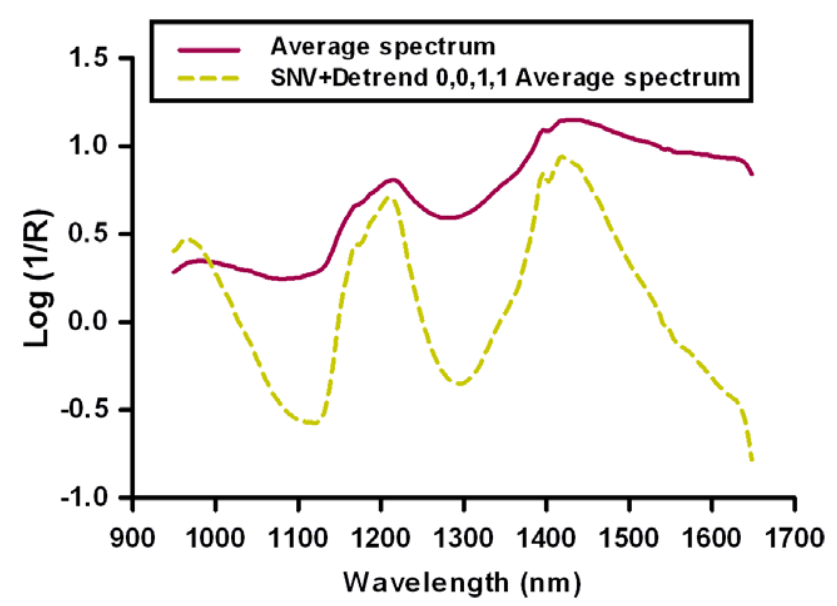

Figure 2. Average and SNV-Detrend spectra of the samples in the NIR zone between 950 and $1650 \mathrm{~nm}$.

Table 1. Calibration statistical descriptors for the models developed in the NIR zone close to $950-1650 \mathrm{~nm}$

\begin{tabular}{|c|c|c|c|c|c|c|c|c|c|c|}
\hline \multirow[b]{2}{*}{ Spectral pre-treatment } & \multirow[b]{2}{*}{ Compound } & \multirow[b]{2}{*}{ T outliers } & \multirow[b]{2}{*}{ PLS factors } & \multirow[b]{2}{*}{$N$} & Est. Min & SD & Est. Max & SEC & \multirow[b]{2}{*}{ RSQ } & \multirow{2}{*}{$\begin{array}{c}\text { SECV } \\
\text { (mg per grape) }\end{array}$} \\
\hline & & & & & \multicolumn{4}{|c|}{ (mg per grape) } & & \\
\hline SNV + Detrend 0,0,1,1 & Total anthocyanins & 3 & 6 & 47 & 0 & 0.96 & 5.37 & 0.51 & 0.72 & 0.78 \\
\hline SNV + Detrend 0,0,1,1 & Non-acylated anthocyanins & 3 & 6 & 47 & 0 & 0.85 & 4.63 & 0.45 & 0.72 & 0.70 \\
\hline
\end{tabular}



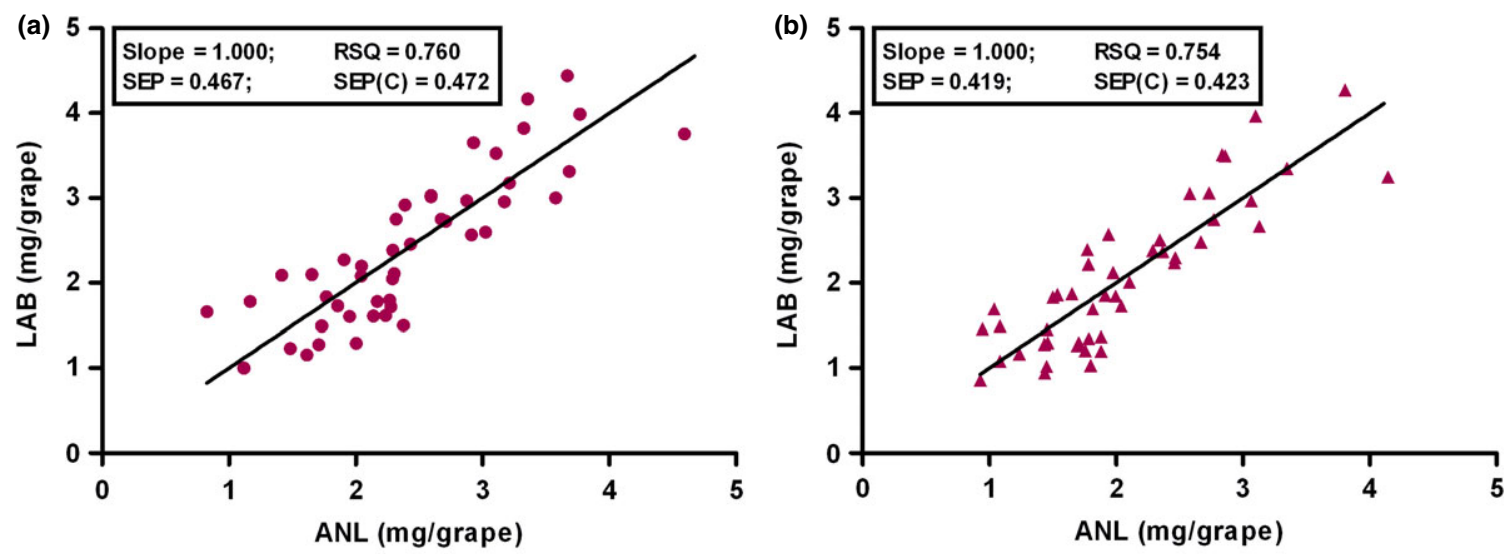

$$
\text { - Total anthocyanins } \quad \text { Non-acylated anthocyanins }
$$

Figure 3. Comparison of HPLC reference value with the values predicted by the hyperspectral imaging models. (a) Total anthocyanins and (b) non-acylated anthocyanins.

stages it was appropriate to face the calibration step using the whole data set.

Finally, quantitative calibrations were developed by modified partial least squares (MPLS) regression using total or non-acylated anthocyanins as the dependent $(Y)$ variable and grape spectra as the independent $(X)$ variables. The statistical parameters of the final calibration equations are shown in Table 1, where $N$ is the number of samples used to obtain the calibration equation after eliminating samples for chemical reasons ( $T$ criterion). The best of the different mathematical treatments, concentration range, and standard deviations are also shown. The average spectrum of the best of the different mathematically pre-treated spectra is shown in Fig. 2. The robustness of the method has been checked by the leave-one-out validation method as stated above. Table 1 also shows the results obtained in the aforesaid procedure as SECV values. These values are comparatively similar to the errors previously reported for these compounds taking into the account the applicability range. ${ }^{7,18-21}$ After three $T$ outliers had been excluded, an internal validation was carried out using samples that belonged to the calibration group and predicting their reference values by the developed models. Figure 3 shows the comparison of predicted values versus the chromatographic data for total anthocyanis and non-acylated anthocyanins in the internal validation, respectively. The obtained results [slope, coefficient of determination (RSQ), standard error of prediction (SEP) and standard error of prediction corrected for the bias $(\operatorname{SEP}(C))$ in the internal validation, respectively] for the developed models were also presented in the above mentioned figure.

The spectral zones around $1150 \mathrm{~nm}$ and $1400 \mathrm{~nm}$ present significant contributions to the model loadings. These may be related to combination bands of the - $\mathrm{OH}$ functional group, symmetric and anti-symmetric stretching. This wavelength region is also related to $\mathrm{C}-\mathrm{H}$ aromatic second overtones and $\mathrm{C}-\mathrm{H}$ third overtones. ${ }^{22,23}$ This is in good agreement with previous studies that showed important contributions in the aforesaid spectral regions for the same phenolic compounds. ${ }^{7,21}$

\section{CONCLUSION}

The potential of near infrared hyperspectral imaging to determine anthocyanins in intact single grapes from La Rioja has been evaluated. The procedure reported here presents a good potential for a fast and reasonably inexpensive screening of these compounds in intact single berries. Moreover, the heterogeneity of anthocyanins within the same ripeness stage could be evaluated using this non-detructive tool. This methodology allows the berries to be sorted according to their anthocyanins content and then the same samples could be used in further studies for other destructive analyses or purposes.

\section{ACKNOWLEDGEMENTS}

The Spanish MINECO is thanked for J. Nogales-Bueno FPI grant (BES-2012-060192), and project AGL2014-58486-C2. J.M. Hernández-Hierro thanks Universidad de Sevilla for the extension of the Juan de la Cierva postdoctoral contract. Francisco J. Rodríguez-Pulido also thanks VPPI-Universidad de Sevilla for a postdoctoral grant. Junta de Andalucía is also thanked for financial support (project P10-AGR6331). The authors also thank Bodegas RODA (La Rioja, Spain) for supplying the grape samples. R. Martínez thanks the National Council for Science and Technology (CONACYT) and also all the people that were involved with this research at the UABC, CICESE and University of Seville. The authors thank the technical staff of the Biology Service [Servicios Generales de Investigación (SGI), Universidad de Sevilla] for technical assistance.

\section{REFERENCES}

1 Boulton R, The copigmentation of anthocyanins and its role in the color of red wine: A critical review. Am J Enol Vitic 52:67-87 (2001).

2 Crozier A, Clifford MN and Ashihara H, Plant Secondary Metabolites. Occurrence, Structure and Role in the Human Diet. Blackwell Publishing, Oxford (2006).

3 Gowen AA, O'Donnell CP, Cullen PJ, Downey G and Frias JM, Hyperspectral imaging - An emerging process analytical tool for food quality and safety control. Trends Food Sci Technol 18:590-598 (2007).

4 Lorente D, Aleixos N, Gómez-Sanchis J, Cubero S, García-Navarrete O and Blasco J, Recent advances and applications of hyperspectral imaging for fruit and vegetable quality assessment. Food Bioprocess Technol 5:1121-1142 (2012).

5 Burger J and Gowen AA, Data handling in hyperspectral image analysis. Chemom Intell Lab Syst 108:13-22 (2011).

6 Nogales-Bueno J, Rodriguez-Pulido FJ, Heredia FJ and HernandezHierro JM, Comparative study on the use of anthocyanin profile, color image analysis and near-infrared hyperspectral imaging as 
tools to discriminate between four autochthonous red grape cultivars from La Rioja (Spain). Talanta 131:412-416 (2015).

7 Hernandez-Hierro JM, Nogales-Bueno J, Rodriguez-Pulido FJ and Heredia FJ, Feasibility study on the use of near-infrared hyperspectral imaging for the screening of anthocyanins in intact grapes during ripening. J Agric Food Chem 61:9804-9809 (2013).

8 Kontoudakis N, Esteruelas M, Fort F, Canals JM, De Freitas V and Zamora F, Influence of the heterogeneity of grape phenolic maturity on wine composition and quality. Food Chem 124:767-774 (2011).

9 Bergqvist J, Dokoozlian N and Ebisuda N, Sunlight exposure and temperature effects on berry growth and composition of Cabernet Sauvignon and Grenache in the Central San Joaquin Valley of California. Am J Enol Vitic 52:1 -7 (2001).

10 Haselgrove L, Botting D, van Heeswijck R, Høj PB, Dry PR, Ford C, et al., Canopy microclimate and berry composition: The effect of bunch exposure on the phenolic composition of Vitis vinifera L. Cv. Shiraz grape berries. Aust J Grape Wine Res 6:141 - 149 (2000)

11 Denominación-de-Origen-Calificada-Rioja, Learn About Rioja. Available: http://es.riojawine.com/en/5-learn-about-rioja/34-learnabout-rioja.html [04 October 2014].

12 Nogales-Bueno J, Hernandez-Hierro JM, Rodriguez-Pulido FJ and Heredia FJ, Determination of technological maturity of grapes and total phenolic compounds of grape skins in red and white cultivars during ripening by near infrared hyperspectral image: A preliminary approach. Food Chem 152:586-591 (2014).

13 García-Marino M, Hernández-Hierro JM, Rivas-Gonzalo JC and Escribano-Bailón MT, Colour and pigment composition of red wines obtained from co-maceration of Tempranillo and Graciano varieties. Anal Chim Acta 660:134-142 (2010).
14 Shenk JS and Westerhaus MO, Routine Operation, Calibration, Development and Network System Management Manual. NIRSystems, Silver Spring, MD (1995).

15 Brereton RG, Chemometrics: Data Analysis for the Laboratory and Chemical Plant. Wiley, Chichester (2003).

16 Geladi P, MacDougall D and Martens H, Linearization and scatter-correction for near-infrared reflectance spectra of meat. Appl Spectrosc 39:491-500 (1985).

17 Dhanoa MS, Lister SJ and Barnes RJ, On the scales associated with near-infrared reflectance difference spectra. Appl Spectrosc 49:765-772 (1995).

18 Kemps B, Leon L, Best S, De Baerdemaeker J and De Ketelaere B, Assessment of the quality parameters in grapes using VIS/NIR spectroscopy. Biosyst Eng 105:507-513 (2010).

19 Cozzolino D, Near infrared spectroscopy in natural products analysis. Planta Med 75:746-756 (2009).

20 Cozzolino D, Dambergs RG, Janik L, Cynkar WU and Gishen M, Review: Analysis of grapes and wine by near infrared spectroscopy. J Near Infrared Spectrosc 14:279-289 (2006).

21 Ferrer-Gallego R, Hernández-Hierro JM, Rivas-Gonzalo JC and Escribano-Bailón MT, Determination of phenolic compounds of grape skins during ripening by NIR spectroscopy. LWT - Food Sci Technol 44:847-853 (2011).

22 Osborne BG, Fearn T and Hindle PT, Practical NIR Spectroscopy with Applications in Food and Beverage Analysis. Longman Scientific \& Technical, Harlow (1993).

23 Siesler HW, Ozaky Y, Kawata S and Heise HM, Near Infrared Spectroscopy: Principles, Instruments, Applications. Wiley-VCH, Weinheim (2002). 